\title{
Family Risk Factors Among Women With Addiction-Related Problems: An Integrative Review
}

\author{
Imaneh Abasi, ${ }^{1}$ and Parvaneh Mohammadkhani ${ }^{1,}$ \\ ${ }^{1}$ Department of Clinical Psychology, University of Social Welfare and Rehabilitation Sciences, Tehran, IR Iran \\ "Corresponding author: Parvaneh Mohammadkhani, Department of Clinical Psychology, University of Social Welfare and Rehabilitation Sciences, Tehran, IR Iran. Tel: \\ +98-2122180045, Fax: +98-2122180045, E-mail: p.mohammadkhani@uswr.ac.ir
}

Received 2015 February 01; Revised 2015 June 08; Accepted 2015 June 19.

\begin{abstract}
Context: Recent years have produced many articles about women's addiction and its risk factors and the consequences of substance use and misuse in the emotional, social, psychological, and economic domains of life. Family vulnerabilities are one of the most important variables contributing to addiction among women. Thus, the purpose of this article is to investigate areas of family life that lead to women's taking up and maintaining drug and alcohol abuse.

Evidence Acquisition: A database search of PubMed, ScienceDirect, Springer, and Google Scholar was conducted using the following keywords: "women and addiction", "women addiction and family", "addiction", "substance abuse" and "family". For the first step, we chose studies that were conducted between 2000 and 2015, and for the second step, studies conducted before 2000 . We categorized all search results into three main groups: processes related to family disturbances, factors related to parenting styles, and variables related to partners.

Results: Partners, parenting styles, and family disturbances are three main factors affecting children growing up in a family and their inclination toward addiction. Some of these pathways are complicated and indirect, and some are straightforward.

Conclusions: Future research should pay more attention to the mechanisms and pathways mediating or moderating the relationship between family risk factors and addiction in women. Clinicians and researchers should keep in mind these vulnerabilities and take into consideration factors special to processes related to addiction in women.
\end{abstract}

Keywords: Women, Behavior, Addictive, Family, Substance Abuse

\section{Context}

Addiction has emerged as a worldwide problem, and the use of alcohol and other drugs has overwhelmingly increased among women (1). Based on criteria specified in the diagnostic and statistical manual of mental disorders (DSM-IV-TR; (2)) in 2009, $6.1 \%$ of the U.S. female population is estimated to experience substance abuse or dependence (3). An international review on substance use by women revealed that women comprised $10 \%$ of the substance-using adult population in several Asian countries, $20 \%$ in postSoviet countries and Latin America, and up to $40 \%$ in North America and in several European countries (4). Generally, women still consume less alcohol and other illicit drugs than men, but some researchers suggest that substance abuse-related problems tend to occur with more severity and rapidity among women than among men (5).

Women's use of substances and alcohol contributes to certain problems and consequences, some of which are common to both genders and some of which are specific to women (6). Impairment in almost all life domains is noted as a result of the comorbidity of substance use and psychi- atric, social, and economic problems (7). Quality of life is another important mental health index that is reduced in women using alcohol and other substances in a dysfunctional way $(8,9)$. Children of alcohol and substance abusing women are also at risk for maltreatment and poor development because of a constellation of risks associated with addiction problems (10), such as a loss of child custody (11) and difficulties in providing for basic family needs (11). The economic costs of families suffering with addiction are high and also need to be considered (12). A large proportion of attention in many studies is given to the most important class of women affected with addiction problems, those who are pregnant. Recent evidence reveals that addiction during pregnancy has emotional, social, psychological, and economical influences on the offspring and on the family in general $(13,14)$.

The abovementioned serious long-term effects have led many professionals and researchers to seek out causes of women's tendency toward drugs and alcohol and the women's continuing to consume them despite their side effects. Some of the factors known to be reasons or risk factors for addition-related problems among women include 
alcohol advertising (15), sexual orientation (16, 17), drinking norms $(17,18)$, a history of abuse $(19,20)$, partner violence (21), and cognitive impairment (22).

As more complex models have emerged explaining the mechanisms of the difficulties related to alcohol and substance abuse, especially among women, they have highlighted the role of family of origin as a risk factor in developing and maintaining addictions and especially as a barrier to addiction treatments.

\section{Evidence Acquisition}

A database search of PubMed, ScienceDirect, Springer, and Google Scholar was conducted, using the following keywords: "women and addiction," "women addiction and family", "addiction", "substance abuse" and "family". Initially, all studies chosen were conducted between 2000 and 2015, but because of the limitation of resources related to family vulnerabilities and risks for women's addiction, studies before 2000 were also included in the data analysis. The full texts of most articles were used; however, some results included abstracts for which the full text was not available. With respect to our research, some articles assessed family-related components that contribute to addiction. Most of these papers attempted to answer their questions using samples that included both genders. For the sake of this review, we chose articles with some implications for women with addiction-related problems. We categorized all evidence into three main groups: processes related to family disturbances, factors related to parenting styles, and variables related to partners.

\subsection{Processes Related to Family Disturbances}

An addicted family is one of the significant factors that may result in addiction in children as well as many other drastic consequences. The mechanism of this effect involves genetic and environmental processes. Children of addicted parents are genetically at the highest risk of becoming alcoholics and drug abusers (23); this risk has been demonstrated even for adopted children whose biological parents suffer from addiction (24). Role modeling has also been shown to contribute in alcohol and substance use in children (25). Some researchers have established that having family members who smoke is a risk factor for smoking uptake and, as such, is a major but entirely avoidable health risk. Notably, the family member whose smoking creates the strongest effect on other individual family members is the mother (26). Drinking norms also exert a serious influence on drinking behavior, and this effect remains stable $(18,27)$; permissive attitudes in an addicted family with respect to drinking alcohol have a profound influence on the attitudes of young family members toward drinking and their own behavior (28). Other studies have demonstrated that patients with a family history of substance use are more likely to have comorbid substance dependencies and more psychological problems $(29,30)$.

Norton (31) (1993) has proposed four systematic processes that operate to lead to a loss of identity of family members and the perpetuation of the system. Norton suggests that these insidious processes create salience and a denial of problems related to addiction coupled with unavoidable stress, trauma, and deprivation. These processes include isolation, inhuman treatment, inconsistency, and indoctrination, and they are interrelated like a system. These four systematic processes may be responsible for the initiation of addiction or psychological problems that may later lead to addiction for family members.

Empirical studies have linked family dysfunction with maladaptive emotion regulation strategies and behaviors, some of which are associated with alcohol and drug use/abuse. For example, family conflict and parental rejection are variables that are found in dysfunctional families and have been related to addiction (32). According to behavioral theories, some of these coping mechanisms may run in a family due to observational learning (33). Another investigation showed that parental addiction is related to child addiction after controlling for parental dysfunctional factors such as warmth and hostility (34). Kluck et al. (35) (2014) found that there is a significant indirect effect of family dysfunction on alcohol-related problems among college women. In another study, participants' addictionrelated behaviors were predicted by parental addictionrelated behaviors. It has been demonstrated that people who become addicted to nicotine later in life have often had some familial dysfunction such as parental loss, poor parental monitoring, parental conflict, and the separation or divorce of parents before age 11 (36). Moreover, family discord has been related to a higher instance of substance abuse in women (14).

\subsection{Factors Related to Parenting Styles}

Family parenting styles play a key role both in inducing risk and in protection and resilience against addiction in individuals. Less emotional warmth and more parental rejection are two parenting style factors associated with substance abuse (37). A review on the number of family processes and structures associated with young people commencing substance abuse and misuse showed significant evidence for family involvement in a young individual's initiation into addiction (38). Families characterized as rigid-disengaged in the Circumplex model seem more likely to contribute to addiction-related problems in the offspring (39). In line with this result, using regression analysis, another study demonstrated that cohe- 
sion and adaptability are negatively correlated with alcoholism, and this relationship is more meaningful in women than in men (40). As another variable, a lack of parenting restrictions also has a strong effect on smoking (41).

Parental styles are among the family variables most widely studied. Many studies investigate parenting styles according to Baumrind's three parenting styles (41-43). A review of the effects of parenting styles on individuals' take-up of addiction as well as risk factors and protective factors, covering studies over the past 30 years, suggested that an authoritative style provides the most protection against substance use, while a neglectful style increases the risk of drug use; however, research on authoritarian and permissive styles is still inconclusive (44).

Hartman et al. (45) (2015) examined the influence of self-concealment ("a predisposition to actively conceal from others personal information one perceives as distressing or negative" (46)) as a parental attitude that mediates or moderates the choice of parenting styles. The sample included 419 university students (223 men, 196 women), and structural equation modeling was used to analyze the data. The results showed that higher levels of authoritarianism in the mother are indirectly linked both to increased alcohol use and to alcohol-related problems; this relationship is mediated by more self-concealment and a more impaired control of drinking. Higher levels of authoritativeness in the father, on the other hand, are indirectly linked to less alcohol use and fewer alcoholrelated problems; this relationship is mediated by less selfconcealment and a less impaired control of drinking.

\subsection{Variables Related to Partners}

The vast majority of studies highlights the role of partners in women's taking up and maintaining drug and alcohol use and misuse and especially in the initiation and following of treatment $(21,47,48)$. A world health organization (WHO) multi-country study (including Bangladesh, Brazil, Ethiopia, Japan, Namibia, Peru, Samoa, Serbia and Montenegro, Thailand, and the United Republic of Tanzania) on 24,097 women aged 15 - 49 years, from 2000 to 2003, showed that the reported lifetime prevalence of physical or sexual partner violence, or both, varies from $15 \%$ to $71 \%$, with two sites having a prevalence of less than $25 \%$, seven between $25 \%$ and $50 \%$, and six between $50 \%$ and $75 \%$. Also, between $4 \%$ and $54 \%$ of participants reported physical or sexual partner violence, or both, in the previous year (49). Other studies show that drug abuse is associated with the severity of physical partner violence (50). Another study reveals that women with addicted husbands have significantly higher scores in all psychiatric symptoms (51) such as antisocial personality, borderline personality, depression, stress, and violence approval related symptoms
(52). It has also been shown that husbands of women with drinking problems tend to be unsympathetic, have stereotypical beliefs about women's roles, and show little interest in their wives' problems (53). Also, men and women with addiction-related problems tend to be couples (54).

Finally, two other factors that are not directly related to addiction in women but which indirectly lead to their alcohol and substance use and abuse include childhood abuse and eating disorders or worries about weight. A history of sexual assault is also strongly associated with women's alcohol use $(17,55)$; one possible explanation of this process may be that women use alcohol to reduce the psychological distress that originates in their sexual assault history (56). A higher instance of alcohol drinking has been reported for lesbian and bisexual women who have a history of sexual abuse than for the general population (16). Eating disorders such as binge eating and anorexia nervosa are highly comorbid with addiction; these occur together in women with addiction problems and occur in the addiction treatment in of who have also been affected by eating disorders (57-59).

\section{Results}

The family is the most basic environment where children grow up, and it has both short and long-term emotional, physical, social, and psychological influences on the children's development toward adolescence and adulthood. So environment and atmosphere of family affect the mental health and psychological wellbeing of its members. There are many familial processes, factors, and vulnerabilities that contribute to individuals internalizing and externalizing problems. This review has categorized all these variables into three major classes: processes related to family disturbances, factors related to parenting styles, and variables related to partners. The results and evidence from the reviewed articles demonstrate that special attention must be paid to these significant components.

Recent addiction treatment strategies have focused seriously on the families of women with addiction-related problems; it is more economical and efficient to discern which of these variables play casual or contributive roles in women's addiction and to try to target these factors in treatment settings. Family therapy approaches may target some spousal and familial dynamics that lead to women's taking up of alcohol and to substance use and abuse.

There are also pathways, mediators, or moderators that may lead either to familial risk or to protective factors. Thus, investigating these pathways/factors and their relationships with familial variables can make a more immediate and straightforward contribution to addiction treatment for women. 


\section{Discussion}

The importance of family risk factors in contributing to addiction-related problems has previously been supported by reviews of cumulative findings; clinicians and researchers should therefore keep these vulnerabilities in mind. There are also some characteristics and issues specific to women that impact the initiation and degree of their substance and alcohol use and how long they are addicted, and these factors should be taken into account both for the effectiveness of treatment and in future studies. The articles reviewed in the present study were not excluded to a female sample, and some did not mention gender classifications, and this may contaminate the results and conclusions of this paper. Thus, in the future, and with more published articles and more databases in hand in order to research female addiction, it will be better to limit review articles and papers just to a female sample.

\section{Acknowledgments}

We thank the University of Social Welfare and Rehabilitation Sciences for providing us with databases and the most recent articles.

\section{Footnote}

Authors' Contribution: Both authors contributed to the literature review, to access to references, and to writing and editing the final manuscript.

\section{References}

1. Greenfield SF. Women and alcohol use disorders. Harv Rev Psychiatry. 2002;10(2):76-85. [PubMed: 11897748].

2. Association AP. DSM-IV-TR. USA: American Psychiatric Association; 2000.

3. Lindsay AR, Warren CS, Velasquez SC, Lu M. A gender-specific approach to improving substance abuse treatment for women: The Healthy Steps to Freedom program. J Subst Abuse Treat. 2012;43(1):61-9. doi: 10.1016/j.jsat.2011.10.027. [PubMed: 22154034].

4. Drugs UNO . Substance abuse treatment and care for women: Case studies and lessons learned. 2004.

5. Ridenour TA, Maldonado-Molina M, Compton WM, Spitznagel EL, Cottler LB. Factors associated with the transition from abuse to dependence among substance abusers: implications for a measure of addictive liability. Drug Alcohol Depend. 2005;80(1):1-14. doi: 10.1016/j.drugalcdep.2005.02.005. [PubMed: 16157227].

6. Nolen-Hoeksema S. Gender differences in risk factors and consequences for alcohol use and problems. Clin Psychol Rev. 2004;24(8):981-1010. doi: 10.1016/j.cpr.2004.08.003. [PubMed: 15533281].

7. Bizzarri J, Rucci P, Vallotta A, Girelli M, Scandolari A, Zerbetto E, et al. Dual diagnosis and quality of life in patients in treatment for opioid dependence. Subst Use Misuse. 2005;40(12):1765-76. [PubMed: 16419555].
8. Rudolf $\mathrm{H}$, Priebe S. Subjective quality of life and depressive symptoms in women with alcoholism during detoxification treatment. Drug Alcohol Depend. 2002;66(1):71-6. doi:10.1016/S0376-8716(01)00183-1.

9. Tracy EM, Laudet AB, Min MO, Kim H, Brown S, Jun MK, et al. Prospective patterns and correlates of quality of life among women in substance abuse treatment. Drug Alcohol Depend. 2012;124(3):242-9. doi: 10.1016/j.drugalcdep.2012.01.010. [PubMed: 22333265].

10. Kyzer A, Conners-Burrow NA, McKelvey L. Environmental risk factors and custody status in children of substance abusers. Child Youth Serv Rev. 2014;36:150-4. doi:10.1016/j.childyouth.2013.11.020.

11. Conners-Burrow NA, Johnson D, Whiteside-Mansell L, McKelvey L, Bokony PA, Bradley RH. Protecting young children: Identifying family substance use and risks in the home. NHSA Dialog. 2010;13(3):168-84. doi: $10.1080 / 15240754.2010 .492360$.

12. Copello A, Templeton L, Powell J. The impact of addiction on the family: Estimates of prevalence and costs. Drugs: Educ Prev Polic. 2010;17(1):63-74. doi: 10.3109/09687637.2010.514798.

13. Benningfield MM, Arria AM, Kaltenbach K, Heil SH, Stine SM, Coyle MG, et al. Co-occurring psychiatric symptoms are associated with increased psychological, social, and medical impairment in opioid dependent pregnant women. Am J Addict. 2010;19(5):416-21. doi 10.1111/j.1521-0391.2010.00064.x. [PubMed: 20716304].

14. Denton WH, Adinoff BH, Lewis D, Walker R, Winhusen T. Family discord is associated with increased substance use for preg nant substance users. Subst Use Misuse. 2014;49(3):326-32. doi: 10.3109/10826084.2013.840002. [PubMed: 24106976].

15. Poole N, Dell CA. Girls, women and substance use CCSA-CCLAT 2005. Available from: http://www.ccsa.ca/Resource\%20Library/ ccsa-011142-2005.pdf.

16. Hughes T. Alcohol-Related Problems among Sexual Minority Women Alcohol Treat Q. 2011;29(4):403-35. doi: 10.1080/07347324.2011.608336. [PubMed: 22470226].

17. Gilmore AK, Koo KH, Nguyen HV, Granato HF, Hughes TL, Kaysen D. Sexual assault, drinking norms, and drinking behavior among a national sample of lesbian and bisexual women. Addict Behav. 2014;39(3):630-6. doi: 10.1016/j.addbeh.2013.11.015. [PubMed: 24360780].

18. O'Grady MA, Cullum J, Tennen H, Armeli S. Daily relationship between event-specific drinking norms and alcohol use: a four-year longitudinal study.J Stud Alcohol Drugs. 2011;72(4):633-41. [PubMed: 21683045].

19. Mouilso ER, Fischer S, Calhoun KS. A prospective study of sexual assault and alcohol use among first-year college women. Violence Vict. 2012;27(1):78-94. [PubMed: 22455186].

20. Mohammadkhani P, Mohammadi MR, Rezaee-Dogaheh E, Nazari MA Trauma symptoms in abused children. J Rehabil. 2003;4(2):20-8.

21. Fowler DN, Faulkner M. Interventions targeting substance abuse among women survivors of intimate partner abuse: a meta-analysis. J Subst Abuse Treat. 2011;41(4):386-98. doi: 10.1016/j.jsat.2011.06.001. [PubMed: 21757316].

22. Viola TW, Tractenberg SG, Pezzi JC, Kristensen CH, Grassi-Oliveira R. Childhood physical neglect associated with executive functions impairments in crack cocaine-dependent women. Drug Alcohol Depend. 2013;132(1-2):271-6. doi: 10.1016/j.drugalcdep.2013.02.014. [PubMed: 23478152].

23. Audrain-McGovern J, Al Koudsi N, Rodriguez D, Wileyto EP, Shields PG, Tyndale RF. The role of CYP2A6 in the emergence of nicotine dependence in adolescents. Pediatrics. 2007;119(1):e264-74. doi: 10.1542/peds.2006-1583. [PubMed: 17130279].

24. Schuckit MA, Goodwin DA, Winokur G. A study of alcoholism in half siblings. Am J Psychiatry. 1972;128(9):1132-6. doi: 10.1176/ajp.128.9.1132. [PubMed: 5060834].

25. Oostveen T, Knibbe R, De Vries H. Social influences on young adults' alcohol consumption: norms, modeling, pressure, socializing, and conformity. Addict Behav. 1996;21(2):187-97. doi:10.1016/03064603(95)00052-6. 
26. Leonardi-Bee J, Jere ML, Britton J. Exposure to parental and sibling smoking and the risk of smoking uptake in childhood and adolescence: a systematic review and meta-analysis. Thorax. 2011;66(10):84755. doi: 10.1136/thx.2010.153379. [PubMed: 21325144].

27. Cullum J, Armeli S, Tennen H. Drinking norm-behavior association over time using retrospective and daily measures.J Stud Alcohol Drugs. 2010;71(5):769-77. [PubMed: 20731984].

28. Bratek A, Beil J, Banach M, Jarzabek K, Krysta K. The impact of family environment on the development of alcohol dependence. Psychiatr Danub. 2013;25 Suppl 2:S74-7. [PubMed: 23995149].

29. Merikangas KR, Mehta RL, Molnar BE, Walters EE, Swendsen JD, Aguilar-Gaziola S, et al. Comorbidity of substance use disorders with mood and anxiety disorders: results of the International Consortium in Psychiatric Epidemiology. Addict Behav. 1998;23(6):893-907. doi: 10.1016/S0306-4603(98)00076-8.

30. Coviello DM, Alterman AI, Cacciola JS, Rutherford MJ, Zanis DA. The role of family history in addiction severity and treatment response. $J$ Subst Abuse Treat. 2004;26(1):1-11. doi: 10.1016/S0740-5472(03)00143-0.

31. Norton JH. Addiction and family issues. Alcohol. 1994;11(6):457-60. doi: 10.1016/0741-8329(94)90066-3.

32. Downs WR, Robertson JF. Family dynamics and adolescent alcohol use: A path analysis with a treatment sample. J Appl Soc Sci. 1987.

33. Bandura A, Ross D, Ross SA. Imitation of film-mediated agressive models. J Abnorm Soc Psychol. 1963;66:3-11. [PubMed: 13966304].

34. White HR, Johnson V, Buyske S. Parental modeling and parenting behavior effects on offspring alcohol and cigarette use: A growth curve analysis. J Subst Abuse Treat. 2000;12(3):287-310. doi: 10.1016/S08993289(00)00056-0.

35. Kluck AS, Carriere L, Dallesasse S, Bvunzawabaya B, English E, Cobb $\mathrm{M}$, et al. Pathways of family influence: alcohol use and disordered eating in daughters. Addict Behav. 2014;39(10):1404-7. doi: 10.1016/j.addbeh.2014.05.015. [PubMed: 24926908].

36. Nurco DN, Kinlock TW, O'Grady KE, Hanlon TE. Differential contributions of family and peer factors to the etiology of narcotic addiction. Drug Alcohol Depend. 1998;51(3):229-37. doi: 10.1016/S03768716(98)00041-6.

37. Barnow S, Schuckit MA, Lucht M, John U, Freyberger HJ. The importance of a positive family history of alcoholism, parental rejection and emotional warmth, behavioral problems and peer substance use for alcohol problems in teenagers: a path analysis. J Stud Alcohol. 2002;63(3):305-15. doi:10.15288/jsa.2002.63.305.

38. Velleman RD, Templeton LJ, Copello AG. The role of the family in preventing and intervening with substance use and misuse: a comprehensive review of family interventions, with a focus on young people. DrugAlcohol Rev. 2005;24(2):93-109. doi:10.1080/09595230500167478. [PubMed:16076580].

39. Friedman AS, Utada A, Morrissey MR. Families of adolescent drug abusers are "rigid": are these families either "disengaged" or "enmeshed," or both?.Fam Process. 1987;26(1):131-48. [PubMed: 3569500]

40. Wampler R, Fischer J, Thomas M, Lyness K. Young adult offspring and their families of origin: cohesion, adaptability, and addiction. J Subst Abuse. 1993;5(2):195-201. [PubMed: 8400841].

41. Koetting O Byrne K, Haddock CK, Poston WS. Parenting style and adolescent smoking. J Adolesc Health. 2002;30(6):418-25. doi: 10.1016/S1054-139X(02)00370-1.

42. Baumrind D. The influence of parenting style on adolescent competence and substance use. J Early Adolesc. 1991;11(1):56-95. doi: 10.1177/0272431691111004.

43. Shakya HB, Christakis NA, Fowler JH. Parental influence on substance use in adolescent social networks. Arch Pediatr Adolesc Med.
2012;166(12):1132-9. doi: 10.1001/archpediatrics.2012.1372. [PubMed: 23045157].

44. Becoa E, Martinez U, Calafat A, Juan M, Fernandez-Hermida JR, Secades-Villa R. Parental styles and drug use: A review. Drugs: Educ Prev Polic. 2012;19(1):1-10. doi:10.3109/09687637.2011.631060.

45. Hartman JD, Patock-Peckham JA, Corbin WR, Gates JR, Leeman $\mathrm{RF}$, Luk JW, et al. Direct and indirect links between parenting styles, self-concealment (secrets), impaired control over drinking and alcohol-related outcomes. Addict Behav. 2015;40:102-8. doi: 10.1016/j.addbeh.2014.08.009. [PubMed: 25241309].

46. Larson DG, Chastain RL. Self-concealment: Conceptualization, measurement, and health implications. J Soc Clin Psychol. 1990;9(4):43955. doi: 10.1521/jscp.1990.9.4.439.

47. Straus MA. Prevalence of violence against dating partners by male and female university students worldwide. Violence Against Women. 2004;10(7):790-811. doi: 10.1177/1077801204265552.

48. Mason R, O'Rinn SE. Co-occurring intimate partner violence, mental health, and substance use problems: a scoping review. Glob Health Action. 2014;7:24815. doi: 10.3402/gha.v7.24815. [PubMed: 25416321].

49. Garcia-Moreno C, Jansen HA, Ellsberg M, Heise L, Watts CH, W. H. O. Multi-country Study on Women's Health, et al. Prevalence of intimate partner violence: findings from the WHO multi-country study on women's health and domestic violence. Lancet. 2006;368(9543):12609. doi:10.1016/S0140-6736(06)69523-8. [PubMed:17027732].

50. Kubiak SP, Arfken CL, Boyd C, Cortina LM. More severe violence exposure associated with poly-pharmaceutical use. Am J Addict. 2006;15(6):457-61. doi: 10.1080/10550490600998583. [PubMed: $17182448]$.

51. Mohammad Khani P, Asgari A, Frouzan SA, Moumeni F, Delavar B. The expression of psychiatric symptoms among women with addicted husbands. Develop Psychol. 2010;22:237-45.

52. Mohammadkhani P. The personal-relationships problems of women with addicted husband: A perspective to their rehabilitation. Res Addict. 2008;9(3):29-47.

53. Selin KH. Coping with alcohol and drug problems-the experiences of family members in three contrasting cultures. Addiction. 2007;102(1):166-70. doi: 10.1111/j.1360-0443.2007.01720.x.

54. Schuckit MA, Smith TL, Eng MY, Kunovac J. Women who marry men with alcohol-use disorders. Alcohol Clin Exp Res. 2002;26(9):1336-43. doi: 10.1097/01.ALC.0000029585.63550.33. [PubMed: 12351927].

55. Testa M, Livingston JA. Alcohol consumption and women's vulnerability to sexual victimization: can reducing women's drinking prevent rape?. Subst Use Misuse. 2009;44(9-10):1349-76. doi: 10.1080/10826080902961468. [PubMed: 19938922].

56. Stewart SH, Morris E, Mellings T, Komar J. Relations of social anxiety variables to drinking motives, drinking quantity and frequency, and alcohol-related problems in undergraduates. $J$ Ment Health. 2006;15(6):671-82. doi:10.1080/09638230600998904.

57. Benjamin L, Wulfert E. Dispositional correlates of addictive behaviors in college women: binge eating and heavy drinking. Eat Behav. 2005;6(3):197-209. doi: 10.1016/j.eatbeh.2003.08.001. [PubMed: 15854866].

58. Warren CS, Lindsay AR, White EK, Claudat K, Velasquez SC. Weightrelated concerns related to drug use for women in substance abuse treatment: prevalence and relationships with eating pathology. $J$ Subst Abuse Treat. 2013;44(5):494-501. doi: 10.1016/j.jsat.2012.08.222. [PubMed: 23107389].

59. Holderness CC, Brooks-Gunn J, Warren MP. Co-morbidity of eating disorders and substance abuse review of the literature. Int J Eat Disord. 1994;16(1):1-34. doi: 10.1002/1098-108X(199407)16:1<1::AIDEAT2260160102>3.0.CO;2-T. 